\title{
A Case Study on the Conceptualization and Teaching Practice of L2 Argumentative Writing Instruction
}

\author{
Zhiying Chen ${ }^{1}$ \\ ${ }^{1}$ Faculty of English Language and Culture, Guangdong University of Foreign Studies, Guangzhou, China \\ Correspondence: Zhiying Chen, Faculty of English Language and Culture, Guangdong University of Foreign \\ Studies, Guangzhou, China.
}

Received: September 8, 2020

Accepted: September 24, 2020

Online Published: October 16, 2020

doi: 10.5539/elt.v13n11p30

URL: https://doi.org/10.5539/elt.v13n11p30

\begin{abstract}
Argumentative writing is one of the main writing types in Second Language Writing (SLW) instruction, as it links with the assessment of language capacity in tests. It is a common course for students of tertiary education, but few instructors have a clear comprehension of it. With the goal of giving circumspect teaching implications, this study serves as an illustration for argumentative writing lecturers in higher education. In this study, semi-structured interview, classroom observation and collected written drafts are used as research tools to discover the conceptualization and teaching practice of two lecturers who are instructing English-major sophomores. The findings show that different teaching beliefs (human-oriented and task-oriented) lead to different teaching process in argumentative writing class. Besides, the assessment criteria and students' response are revealed to understand the effects of those instructions accordingly.
\end{abstract}

Keywords: second language writing, argumentative writing, pedagogy, green teachers

\section{Introduction}

Argumentative writing is a typical tool for assessing student writers' language capacity in TOEFL, IELTS and so on, but learners seem to have difficulty in producing argument in EFL contexts (Bacha, 2010). Some of the studies indicate that the writing difficulty lies in the negative transfer between the first and the second language (Connor, 1987; Connor \& Kaplan, 1987). However, there are studies claiming that learners are able to overcome such difficulty of cultural parameter with appropriate instructions (Connor, 2001; Kaplan, 2001). The development of argumentative writing is supposed to be essential (Mercer, 2009) as it is related to the experiences of both academic life and everyday life (Kuhn, 2005). Hirvela (2017) suggests more research on argumentative writing instruction as the current studies are insufficient, particularly on the teaching conceptualization and teaching practice. Argumentation is hard to acquire because it involves both thinking skills and discourse skills (Kuhn, 2005). The quality of an argument can vary from one to another with accordance to individual expertise (Goldstein, Crowell, \& Kuhn, 2009), leading to the important role of argumentative writing instruction. Moreover, though the evaluation of argument can be achieved through the analysis of structure and the quality of rebuttals (Erduran, 2007), it becomes more complicated when it comes to the assessment of an argumentative essay. Consequently, argumentative writing instruction is full of challenges to teachers (Kelly, Regev, \& Prothero, 2007), especially for green teachers.

The present study is to compare the teaching styles of two instructors who are lecturing English-major sophomores on Chinese tertiary educational context. Semi-structured interview is carried out to have in-depth qualitative analysis, with classroom observation and collected written drafts as supporting evidence. The aim of this study is to dig into the conceptualization and teaching practice of SLW lecturers to address the questions of how to improve student's writing competence in argumentative writing class. In other words, it consists of three aspects: [i] how instructors conceptualize argumentative writing instruction, including students' foundation, teaching beliefs and the acquisition of argument; [ii] how the argumentative writing pedagogical process is arranged to facilitate the teaching and learning; [iii] how the argumentative writing papers are assessed as well as which part works for the students.

In this study, two different instructional styles are compared to figure out what teaching features are suitable for the argumentative writing class in Chinese higher education. Conclusions are drawn on the teaching approaches of argumentative writing and the improvement of SLW capacity. By providing teaching implications, this study 
is going to rekindle other writing teachers' thoughts and applications.

\section{Review of the Literature}

In the field of SLW, numerous aspects have been explored by researchers, such as the, differences between L1 and L2, writing beliefs, voice, argumentative writing etc. They are not isolated, but sometimes united together as a more comprehensive way to explore SLW.

In cross-language writing, differences and similarities between L1 and L2 explicitly exist, but few focuses on the underlying reasons. In terms of differences, it is said that student writers spend more time pausing (Hall, 1990; Pennington \& So, 1993) and rereading the texts (Pennington \& So, 1993) in L2 contexts, as well as write shorter L2 articles (Berman, 1994; Friedlander, 1990; Hall, 1990). However, Jones and Tetroe (1987) measure the quality of cross-language writing performance, from which the similarity is found in writing strategies for multilingual students. The above evidences seem to neglect the corresponding cognitive and cultural features of a particular language. Actually, SLW is different from creating compositions in the native language both linguistically and culturally (Kirkpatrick, 2017), as this process requires the student writers to shift between the two linguistic domains cognitively (Majchrzak, 2018), but that is often considered as a weakness in L2 writing. What's worse, in many cases, the background knowledge of L1 is ignored as if the student writers are just 'monolingual' and the fixed five-paragraph structure is forced to the students as a form of standard argumentative writing. That is to say, the social cultural aspects are on the cold shoulder and need more exploration in this study.

Both student's beliefs and teacher's beliefs about argumentative writing have been studied by lots of researchers. In the one hand, student's beliefs about academic writing in particular (Wan, 2014; White \& Bruning, 2005) are studied while Hawthorne (2008) shed spotlight to student's beliefs about writing in general. It is supported that argumentative writing is distinct from the general writing in student's minds and worth further study. Still, though the relationship between students' writing beliefs and the outcome of the writing quality differs from one another to some extent (Baaijen, Galbraith \& de Glopper, 2014; Neely, 2014), it is necessary for SLW lecturers to shade a proper and unambiguous understanding of argumentative writing onto student's mind, so that the writing quality can be improved. In the other hand, teachers' orientated beliefs about SLW are studied (McCarthey \& Mkhize 2013). Casanave (2004) indicated that teachers' invisible beliefs and assumptions reflect on their choices and behaviors in the classroom unconsciously, which further proves the importance of one's conceptualization and beliefs. Though there may be a clash between teachers' beliefs and real practice (Melketo, 2012), the underlying conceptualization still guilds the teaching practice.

Some of the present studies pay close attention to the textual features of voice (Hyland, 2012; Matsuda \& Tardy, 2007; Tardy, 2012) while the others break through the composition's limits and expand to the identity of SLW (Harklau, 2000; Peirce, 1995; Starfield, 2002). Hyung-JoYoon (2017) investigates the quantity and diversity of textual voice elements contribute to holistic voice strength and essay quality in EFL argumentative writing. How student writers construct their voice in L2 argumentative writing has a great influence to the essay quality, so the lecturers are supposed to teach the writing strategies, which is in consistence with one of the lecturers' perspective in this study.

There are some studies exploring different aspects of L2 argumentative writing particularly. Based on argumentative writing corpus, the relationship between L2 capacity and linguistic pattern of argument, such as analyzing phrase complexity (Lan, Lucas, \& Yachao, 2019) and lexical bundles (Bychkovska \& Lee, 2017). Though argumentative writing plays a central role in the teaching and learning of tertiary education, but it is taught implicitly with the assumption that students have known this 'common sense' (Coffin, 2004), and thus it is still necessary to find out more effective teaching strategies in Chinese tertiary education. To a broader sense, the SLW teaching strategies can be divided into three categories, that is product approach (Silva, 1990; Brown, 2001), process approach (Silva, 1983) and genre-based approach (Hyland, 2003a; Hyland, 2003b). As we are discussing the SLW on English major students, the first two categories can be seen in this paper. Moreover, the counter-effects on the cultivation of critical thinking and argumentative writing are investigated even from the wash-back of high-stakes tests (Liu \& Stapleton, 2014). It is not surprising that examining the argumentative writing instruction is indispensable as it is regard as a tool to nurture critical thinking in SLW. To reveal the logic of argumentative writing, cohesive features from writer's angle (Liu \& Braine, 2005) and reader's recreation (Basturkmen \& Randow, 2014) are also a hot topic in SLW. Means and Voss (1996) put forward the conceptualization of bringing authentic tasks to the argumentative writing class aiming to develop learners' writing skills. Driver Newton and Osborne (2000) conduct classroom-based study and find out that teachers are lack of pedagogical skills in organizing argumentative discourse in the field of science education. Since Hirvela 
(2017) suggests that SLW researchers should not miss the boat of argument, further discussions about the importance of argumentative writing (Kirkpatrick, 2017), methods to enhance the argumentative writing in the disciplines (Pessoa, 2017) and the assessment on argumentative writing (Plakans \& Gebril, 2017) have been released.

After having a brief review of previous literatures, there is a gap because few studies exploring the conceptualization and teaching practice in details. Consequently, this study is going to further discuss those questions related to L2 argumentative writing instruction.

\section{Methodology}

There are two research subjects whose background information is listed as followings. One subject (named A1) is a professor with nineteen-year writing teaching experience to the university, including students and green teachers. He is not only a distinguished expert majoring in humanities and teacher development, but also a famous instructor in the field of English writing. Another subject (named A2) is an American instructor who has been teaching English courses in China for four years. With a master degree of English literature, he mainly teaches fiction writing, argumentative writing and literature appreciation. The present study is conducted in the second semester when these two instructors are teaching the same course named Intermediate English Writing, which mainly focuses on argumentative writing. Each of them teaches two different classes of English-major sophomores.

The research method of this study is semi-structured interview, classroom observations and written drafts collected. Addressing the first research question, semi-structured interview is conducted with the above mentioned two teachers to draw out their conceptualization of argumentative writing instruction at the end of the semester. The interview process is audio-recorded with A1 in Chinese and with A2 in English separately. To answer the second research question, the author attends the class regularly and writes down the teaching steps in a note-book. The whole teaching process has been audio-recorded to capture instructors' teaching practices particularly. Responding the last research question, 98 pieces of written drafts which have been graded are collected to find out the evaluation criteria and text quality.

To analyze the collected data, NVivo11.0 software is used to encode the transcripts of audio-recording with accordance to the qualitative analysis scheme of Miles and Huberman (1994). The author read through the transcripts of each participant carefully and repeatedly, using open coding and axial coding until a satisfactory framework is finally reached with reference to the existing literature. As observer and researcher, the author attends the classes regularly, discusses with these two teachers wholeheartedly and reflects thoroughly with the existing teaching awareness.

\section{Data Results}

The data results are presented in two aspects, including the conceptualization of argumentative writing instruction and the real teaching practice.

\subsection{Conceptualization of Argumentative Writing Instruction}

Q1: What are the challenges or problems for students in argumentative writing?

A1: So far, due to the traditional Chinese culture (sensitive) is deep rooted in student's mind, their articles are expressive. It can be seen from their papers that the expression is subjective and full of personal feelings or emotions. It is lack of objective and logical evidence. Also, Chinese students believe it is necessary to keep harmony with others and make no argument. As a result, student writers are not familiar with arguing or persuading when writing the L2 papers. Argumentative writing is used as a way to judge student's language competence in tests. Student writers have encountered this kind of writing in high school, but the teaching and learning is so superficial that it mostly focuses on the structure and linguistic form, not the cognitive awareness.

A2: If you write something that you do not believe, it would be hard for the readers to be convinced. Chinese student writers have not done enough thinking about the topics, but just cater to the tests. Their passage is mechanic in a way that full of similar expressions. For example, with the development of technology (or reform and opening up), cellphone has played an important role in changing our life style. Many of them write such kind of beginning sentence at the first time of assignments. This is a failure to arise readers' thinking or feelings.

These two answers look into the same issue from different angles. A1 puts more emphasis the contents, which are sensitive and expressive because student writers set down their thoughts based on the culture of their first language. That is to say, such argumentation is the witness of cognitive transfer between two language domains. Differently, A2 accentuates that reader's response or reaction is on the concern of argumentative writing. Their 
contents are so conservative that it is hard to stimulate mutual or opposite opinions. The underlined reason may account for the former test-oriented teaching and learning approach and students just write down some of the memorized sentences without critical thinking. Both of the answers present the reality of argumentative writing in Chinese tertiary education to some extent and the combine of them may give a more comprehensive picture about its actual situation.

Q2: What do you think of the argumentative writing instruction? Or what are your teaching beliefs? Will you limit the writing topics?

A1: I believe that theoretical knowledge acquired from the class is easily forgotten without putting it into practice. However, one's actual experience will stay in mind for so long as it is part of your life. As a result, my teaching strategies are inclined to encourage learners to write about personal experience and thoughts of real life. Student writers are given the chance to practice how to argue, persuade and convince others in class, such as holding a debate. When writing argumentation, the ubiquitous assumption is that the reader is skeptical, doubtful and critical about your idea. With suitable guide-lines, students begin to argue in group and make sense of that assumption. The firsthand experience is important for writing argument critically.

The topic is not limited in class. Students are supposed to struggle themselves to find a suitable topic and ways of expression. In this way, their thinking map is activated. They learn to negotiate with themselves and step further to the writing requirement. Hopefully, every student will participant in the activity with unique thinking pattern. It is not surprised to find how wonderful their drafts would be, if their creativity has been stimulated.

A2: I have no idea. I just teach the way I teach. If you ask me about how everyone else does it, I have no idea. It seems that the Chinese students are lack of writing skills. There are some writing strategies that can be taught to improve their writing competence. The brainstorming is an effective way to train critical thinking. The argumentation is divided into introductory part, main body and conclusion. I will teach each part separately and bring them together into the whole pages.

I do not limit the topics. Students can write whatever they are interested in, except obsolete topic. Most of the Chinese students would like to write about the advantages or disadvantages of mobile phone, which is not encouraged.

From the above evidence, it can be found that Al's teaching method is much more human-oriented, which takes one's uniqueness into consideration in argumentative writing class. A2's answer seems to be task-oriented as he focuses on whether the students have written professional paper. Also, he seems to be lack of professional training in how to teach argumentation. This is a coincidence with the situation that many pre-service teachers are trained to be English teacher instead of writing teacher (Cheung, 2011; Lee, 2008).

Q3: How and where do you learn to teach argumentative essays?

A1: Majoring in humanities and teacher development, I acquired the human-oriented concepts from my readings, observation and reflection. I am familiar with the nature of Chinese culture. Living in China over a half century, I have witnessed the social changes and culture development. Moreover, I studied my doctor degree in America, which had exposed me to the foreign culture and L2 writing. With the familiarity of Chinese culture and experience of being abroad, the distinctions between L1 and L2 writing are on the lip of the teacher.

A2: I learned from the school experience because in American university, the professors teach how to think diversely. I did observe that from America and adapted it to my teaching class here. I do not copy the American way, but I try to figure out how it works in China since I have been here for several years. I write papers for a big part of my life. The biggest reason is that I think about writing a lot. I chose the sample passage because I like it so much. In the same time, I also control the profession level based on the class's foundation. When I teach academic writing, I will be more professional. This class is a general one and I use the staff in the textbook. The way I teach is from my cultural background and personal experience.

Q4: What are the purposes of argumentative writing? Or what are the application scenarios of argumentative essays?

A1: Well, argument have lots of purposes, such as to prove that our position on a subject is reasonable, to influence the way others think about a subject, to persuade others to change their points of view or to take some sorts of action... and this kind of writing can be applied to a wide range of the situations, including daily issues and professional tests. It is believed that argumentative writing can also serve as a way to train critical thinking.

A2: The purpose of argumentation is to go through academic predicament, since it can be applied to school exams and dissertation. The successful training of critical thinking is the goal of some of the students. In the 
interview, the teacher said that there is about $60 \%$ learning to argue and $40 \%$ arguing to learn. It is supposed that someone would reap the benefit of professional and critical thinking in the condition of others just sitting through the class. The writing strategies should be taught in a professional way.

\subsection{The Teaching Practice of Argumentative Writing}

The teaching practice of argumentative writing is going to be revealed from the teaching process of the second class as an example, the assessment criteria and students' responses.

\subsubsection{The Teaching Process}

Q5: What are the instructional moves, activities and materials and what task do teachers assign in the argumentative writing class?

A1 begins the class with giving students a brief idea of what argument is. Students used to learn exposition, narrative writing and writing after reading class in the last semester and now are going to explore argumentative writing. 1) A lot of daily situations, such as dormitory, home, class and shopping mall, are listed to inspire student's experience 2) Questions are asked about what consequence will be caused after argument? What are the reasons accounting for the consequence? 3) Show a real experience of the teacher and then ask whether student is willing to share. 4) Ask students to write an argumentation on their interests and then A1 walk around the classroom to observe. 5) After finishing, form a pair and try to disagree with the paper to practice aggressive readers. 6) Conclude that the mainstream of the papers is expressive writing which is full of emotions and feelings, except few logical writing. 7) How to produce good argument? Ask students to read the passage on the textbook and look for characteristics of argumentative writing. 8) Explain the content of the sample passage in paraphrasing and write in the blackboard its distinguished components.

Apart from teacher's instruction, group activity is used as a way to practice argument and share opinions. The teaching materials are held in the teacher's mind rather than in the textbook. The listed argument situation and writing topics are closely related to daily issues, with the aim of arousing personal experience. Since A1 is lived in China foe decades, he can count the culture-related topics at ease. He relates the argumentative writing to the daily argument students have experienced. The tasks are to think about certain questions, write the whole argument and practice argument in pair/group.

In A2's perspective, argumentation is basically divided into three parts, which consists of introductory part, the main body and conclusion. The hook in the first part is the main content of the second class. The teaching procedures are 1) Introduce the necessary components of the introductory part. This part should be organized in order, namely introduce the topic, pick up a very specific part of it to talk about, show its importance, create a compelling hook and clearly state the thesis. 2) Two invalid examples of the beginning sentence written by the Chinese student are listed. 3) Seven strategies for writing a hook are taught: anecdotes; question; quotation and explanation of choosing this quote; statistics; setting s scene or describing the situation; a simple and clear definition of the topic; description of the opposite argument. Usually, a good introductory part mixes up with more than one hook. 4) Examples of successful hook are showed and ask students to identify the hook strategies. And then with the replacement of the above two invalid beginning sentence, the hook fails to achieve the reader's interest. 5) Russel's Fear of Public Opinion with modification is analyzed. A2 explains the first paragraph with the skill that he can talk five minutes about one sentence, showing how to think critically. 6) The rest paragraphs are assigned to the student groups to discuss with questions listed as guild-line for students to think about.

The teaching activities are teacher's instruction and group work. This group work is different from Al's for its goal is to train students' thinking with the help of the listed questions. The teaching materials include document which is originally created by the teacher for explanation of the writing strategies, teacher's favorite passage and former sentences written by other students. The assignments are to think about certain questions in group, write the introductory part after the class. In the following classes, the main body and conclusion parts are taught respectively.

Q6: How students' first language or cultural background is used in the argumentative writing class?

A1: During the class, when necessary explanation of the concepts occurred, A1 will switches to Chinese to emphasize the point. For example, those people who always hold opposite opinion to others regardless of correctness are named “杜精” in Chinese. The class bursts into laughter at that moment and attention is drawn back from other distractions. Also, when comparing the thinking map between Chinese and western countries, the first language is spoken in order to capture students' cognition and to help them recognize the problem more clearly. In broader sense, A1 will refer to the cultural background when generating argument topics. For instance, 
the style of washing body is different in the south and north China. If people from these two areas live in one dormitory, there supposed to be argument. Chinese teacher discusses this issue as a topic, which is rooted in the Chinese culture.

A2: The American teacher does not speak Chinese in the campus, the whole teaching process is rarely in Chinese. Since he has been in China for 4 years and travelled a lot, he knows some of the Chinese culture. When listing writing examples in class, he will make a comparison between the Chinese and American ways of doing things. Student's cultural background is not the main concern of the teacher.

Q7: Is argumentative reading a means of instruction in the class?

Yes, both of the teachers account for argumentative reading as a way of learning to argue. The structure of the sample passage is analyzed so as to know how to organize argumentative writing. Its content is explained in paraphrasing and served to motivate critical thinking. That is "arguing to learn". A sense of argumentative writing is formed through argumentative readings and reflection. After analyzing the standard argumentative writing paper, students have the opportunity to practice what they have learned to real writing.

\subsubsection{Evaluation Criteria and Students' Response}

Q8: How argumentative writing can be assessed?

A1: The assessment standard consists of four parts, for each has different proportions. Logic covers $20 \%$, content $40 \%$, language $30 \%$ and structure $10 \%$.

As shown above, teacher attacks great importance to the content and language. The edge between the content and logic is distinctive in this kind of assessment, but actually, it is blurred in some way. However, his kind of criteria is commonly used among SLW instructors because of its easy management.

A2: I would suggest these grading criteria for the essay: Topic specificity--have they clearly specified their topic and showed its importance? Hook--have they used two different techniques and created an emotional effect? Thesis--do they clearly say their main argument?

From this assessment, the introductory paragraph is divided into three pieces to meet such criteria. It is of greater details than the former elevation standard and it is based on argumentative writing strategies that the lecturer has taught in class. Serving as an exact and clear way, it is effective to judge whether student writers have mastered the professional writing skills.

Q9: How do learners response to the argumentative writing class? To be specific, which part works for them?

A1: During the observation, students begin to realize the sensitive nature of Chinese people and avoid being sentimental consciously. In the discussion process, students would remind each other to be objective and to give enough evidences to prove the statement. Fact speaks louder than opinion in the supporting parts of the argumentative writing. Student writers come to know their weakness and try to strengthen the logical thinking step by step. They perform better and better in the part of group discussion and tend to achieve the main functions of argumentative writing. Their thinking process changes from expressive to logical.

A2: Their papers become more professional, as more writing strategies are used under the explicit argumentation instruction. As shown from students' drafts, some of the student writers fail to follow the assignment's requirement because they write more like a whole passage than an introductory paragraph in the second class. It may be due to their acceptability level for the professional training. The class is engaging itself in analyzing the writing strategies, which may be hard for students to master.

\section{Discussion}

To conclude, the teaching conceptualization of the two instructors is different as A1 is based on human-oriented perspective while A2 concerns with task-oriented perspective. The Chinese teacher believes that the written drafts are sensitive because students' non-linear thinking pattern is deep rooted in the Chinese culture, which is distinguished from the linear thinking in western countries. He employs debate as a teaching tool for students to have cognitive foundation for argumentation (Garcia-Mila \& Andersen, 2007), but it is difficulty to organize high-quality classroom debates (Andriessen, 2009). His teaching conceptualization originates from his learning and teaching experiences home and abroad. However, the American teacher deems that their expressions are mechanic for the lack of writing strategies and critical thinking. He uses the brainstorming in group and teaches the fixed framework of argumentative writing to improve students' writing competence. His teaching beliefs are on the foundation of his writing experiences in American college writing center. Their similarity lies in the unlimited writing topic and the function of argumentative writing which is to nurture critical thinking. 
Regarding the teaching practice, both of the instructors employ teacher instruction and group activity as teaching approaches, though the teaching content is different. Though peer assessment is often involved, the epistemic aspects of argument itself are neglected as students tend to evaluate argument based on their own preference (Kuhn, 2005). Thus, evaluation training and immediate feedback are needed (Larson, Britt, \& Kurby, 2009). Besides, they both make good use of students' cultural background and argumentative reading as teaching resources. The teaching design is reasonable as the shared learning context should be fully used to stimulate students' eagerness of learning (Quintana et al., 2004) and read-to-argue is an effective and efficient way to help students learn argumentation (Higgins, 1993). Read-to-argue requires instructor to have strategic teaching skills (Lu \& Deng, 2013). The first language of the students is well organized in A1's class, but neglected in A2's. Apart from the textbook, A2 writes online documents as additional teaching materials while A1 just talks about his thoughts in mind. The evaluation criteria can be distinguished according to the assigned writing task. For a whole passage, there are four aspects that can used to assess an argumentative writing article, namely logic, content, language and structure. For a specific paragraph, more detailed evaluation criteria about each part of the argumentative writing can be used. Chinese students are more adaptive to the first type of evaluation because it is less professional.

\section{Implications of the Findings}

Argumentative writing instructors may reflect and improve their own teaching in accordance with the teaching strategies of this study that the two lecturers have applied. Firstly, it is known that cultural differences in thinking pattern exist as Chinese students may highlight morality than logic, instructors should help to practice those students' critical thinking in argumentative writing. Furthermore, it is probably true that the distinction between process and product approach can be recognized here. Student writers have plenty of opportunities to experience the arguing and thinking process while the other class follows the rules of the final argumentative writing products and try to imitate them. Lastly, from the assessment and students' response, it is easy to figure out which part of the class activities is suitable to their foundations. Lecturers may ferret out learners' need and challenges in this part and step further to adjust their argumentative writing instruction accordingly. To break through the bottleneck of argumentative writing instruction in higher education of SLW, the author believes the combination of human-oriented and task-oriented teaching approaches will be the trend in future.

\section{Conclusions}

This study compares and analyzes two teachers' conceptualization of argumentative writing instruction and its teaching practice accordingly, each of which has distinct teaching features, as one is human-oriented while the other is task-oriented. To improve learners' writing competence, it is necessary to make good use of the available resources in the learning context. Apart from the frequently used group activity, the learning method read-to-argue should not be ignored. Training students' critical thinking and professional writing format is a must in the argumentative writing class. Instructors are supposed to cultivate their own teaching conceptualization consciously and put it into practice effectively. By reflecting their own teaching regularly, chances are that their argumentative writing instruction would be more fruitful.

\section{References}

Andriessen, J. (2009). Argumentation in higher education: examples of actual practices with argumentation tools. In N. M. Mirza, \& A.-N. Perret-Clermont (Eds.), Argumentation and education: Theoretical foundations and practices (pp. 195-213). Dordrecht: Springer. https://doi.org/10.1007/978-0-387-98125-3_8

Baaijen, V. M., Galbraith, D., \& de Glopper, K. (2014). Effects of writing beliefs and planning on writing performance. Learning and Instruction, 33, 81-91. https://doi.org/10.1016/j.learninstruc.2014.04.001

Bacha, N. N. (2010). Teaching the academic argument in a university EFL environment, Journal of English for Academic Purposes, 9(3), 229-241. https://doi.org/10.1016/j.jeap.2010.05.001

Basturkmen, H., \& Janet von Randow. (2014). Guiding the reader (or not) to re-create coherence: Observations on postgraduate student writing in an academic argumentative writing task. Journal of English for Academic Purposes, 16, 14-22. https://doi.org/10.1016/j.jeap.2014.07.005

Berman, R. (1994). Learners' transfer of writing skills between languages. TESL Canada Journal, 12(1), 29-46. https://doi.org/10.18806/tesl.v12i1.642

Brown, H. D. (2001). Teaching by Principles: An Interactive Approach to Language Pedagogy (2nd Ed.). California: San Francisco State University.

Bychkovska, T., \& Joseph, J. Lee. (2017). At the same time: Lexical bundles in L1 and L2 university student 
argumentative writing. Journal of English for Academic Purposes, 30, 38-52. https://doi.org/10.1016/j.jeap.2017.10.008

Cheung, Y. L. (2011). Teacher training for effective writing instruction: Recent trends and future directions. Procedia Social and Behavioral Sciences Journal, 15(1), 531-534. https://doi.org/10.1016/j.sbspro.2011.03.136

Coffin, C. (2004). Arguing about How the World Is or How the World Should Be: The Role of Argument in IELTS Tests. Journal of English for Academic Purposes, 3(3), 229-246. https://doi.org/10.1016/j.jeap.2003.11.002

Connor, U. (2001). Contrastive rhetoric: New directions. paper presented at the second international conference on contrastive rhetoric: Linguistics, culture, and teaching. The American University in Cairo.

Connor, U., \& Kaplan, R. (1987). Writing across languages: Analysis of L2 text. In Addison Wesley (Ed.), Reading (pp. 57-71), Mass.

Driver, R., Newton, P., \& Osborne, J. (2000). Establishing the norms of scientific argumentation in classrooms. $\begin{array}{lll}\text { Science } & \text { Education, } & \text { 287-312. }\end{array}$ https://doi.org/10.1002/(SICI)1098-237X(200005)84:3<287::AID-SCE1>3.0.CO;2-A

Erduran, S. (2007). Methodological foundations in the study of argumentation in science classrooms. In S. Erduran, \& M. P. Jiménez-Aleixandre (Eds.), Argumentation in science education (Vol. 35; pp. 47-69). Netherlands: Springer. https://doi.org/10.1007/978-1-4020-6670-2_3

Friedlander, A. (1990). Composing in English: Effects of a first language on writing in English as a second language. In B. Kroll (Ed.), Second language writing: Research insights for the classroom (pp. 109-125). New York: Cambridge University Press. https://doi.org/10.1017/CBO9781139524551.012

Fulan, L., \& Stapleton, P. (2014). Counterargumentation and the cultivation of critical thinking in argumentative writing: Investigating washback from a high-stakes test. System, 45, 117-128. https://doi.org/10.1016/j.system.2014.05.005

Garcia-Mila, M., \& Andersen, C. (2007). Cognitive foundations of learning argumentation. In S. Erduran, \& M. P. Jiménez-Aleixandre (Eds.), Argumentation in science education (Vol. 35; pp. 29-45). Netherlands: Springer. https://doi.org/10.1007/978-1-4020-6670-2_2

Goldstein, M., Crowell, A., \& Kuhn, D. (2009). What constitutes skilled argumentation and how does it develop? [argument; argumentation; development; metacognition; causal reasoning]. Informal Logic, 29(4), 379-395. https://doi.org/10.22329/il.v29i4.2905

Hall, C. (1990). Managing the complexity of revising across languages. TESOL Quarterly, 24(1), 43-60. https://doi.org/10.2307/3586851

Harklau, L. (2000). From the "good kids" to the "worst": Representations of English language learners across educational settings. TESOL Quarterly, 34, 35-67. https://doi.org/10.2307/3588096

Hawthorne, S. (2008). Students' beliefs about barriers to engagement with writing in secondary school English: A focus group study. Australian Journal of Language and Literacy, 31(1), 30-42.

Higgins, L. (1993). Reading to argue: helping students transform source texts. In A. Penrose, \& B. Sitko (Eds.), Hearing ourselves think: Cognitive research in the college writing classroom (pp. 70-101). New York: Oxford University Press.

Hirvela, A. (2017). Argumentation \& second language writing: Are we missing the boat? Journal of Second Language Writing, 36, 69-74. https://doi.org/10.1016/j.jslw.2017.05.002

Hyland, K. (2003a). Second Language Writing. Cambridge, UK: Cambridge University Press.

Hyland, K. (2003b). Genre-based Pedagogies: Asocial Response to Process. Journal of Second Language Writing, 12(1), 17-29. https://doi.org/10.1016/S1060-3743(02)00124-8

Hyland, K. (2012). Disciplinary identities: Individuality and community in academic discourse. Cambridge: Cambridge University Press.

Hyung-Jo Yoon. (2017). Textual voice elements and voice strength in EFL argumentative writing. Assessing Writing, 32, 72-84. https://doi.org/10.1016/j.asw.2017.02.002

Jones, S., \& Tetroe, J. (1987). Composing in a second language. In A. Matsuhashi (Ed.), Writing in real time (pp. 34-57). Norwood, NJ: Ablex. 
Kaplan, R. (2001). Telepress conference. The second international conference on contrastive rhetoric: Linguistics, culture, and teaching. The American University in Cairo, 23-25.

Kelly, G. J., Regev, J., \& Prothero, W. (2007). Analysis of lines of reasoning in written argumentation. In S. Erduran, \& M. P. Jiménez-Aleixandre (Eds.), Argumentation in science education (Vol. 35; pp. 137-158). Netherlands: Springer. https://doi.org/10.1007/978-1-4020-6670-2_7

Kirkpatrick, A. (2017). How important is argument? Journal of Second Language Writing, 36, 81-82. https://doi.org/10.1016/j.jslw.2017.05.006

Kuhn, D. (2005). Education for thinking. Harvard University Press, Cambridge, Massachusetts.

Lan, G., Lucas, K., \& Yachao, Sun. (2019). Does L2 writing proficiency influence noun phrase complexity? A case analysis of argumentative essays written by Chinese students in a first-year composition course, System, 85, 1-13. https://doi.org/10.1016/j.system.2019.102116

Larson, A. A., Britt, M. A., \& Kurby, C. A. (2009). Improving students' evaluation of informal arguments [Article]. Journal of Experimental Education, 77(4), 339-366. https://doi.org/10.3200/JEXE.77.4.339-366

Lee, I. (2008). Understanding teachers' written feedback practices in HongKong secondary classrooms. Journal of Second Language Writing, 17(2), 69-85. https://doi.org/10.1016/j.jslw.2007.10.001

Lu, J., \& Deng, L. (2013). Examining students' use of online annotation tools in support of argumentative reading. Australasian Journal of Educational Technology, 29(2), 161-171. https://doi.org/10.14742/ajet.159

Matsuda, P. K., \& Tardy, C. M. (2007). Voice in academic writing: The rhetorical construction of author identity in blind manuscript review. English for Specific Purposes, 26, 235-249. https://doi.org/10.1016/j.esp.2006.10.001

McCarthey, S. J., \& Mkhize, D. (2013). Teachers' orientations towards writing. Journal of Writing Research, 5(1), 1-33. https://doi.org/10.17239/jowr-2013.05.01.1

Means, M. L., \& Voss, J. F. (1996). Who reasons well? Two studies of informal reasoning among children of different grade, ability, and knowledge levels. Cognition and Instruction, 14(2), 139-178. https://doi.org/10.1207/s1532690xci1402_1

Meihua, Liu, \& Braine, G. (2005). Cohesive features in argumentative writing produced by Chinese undergraduates. System, 33(4), 623-636. https://doi.org/10.1016/j.system.2005.02.002

Melketo, T. A. (2012). Exploring tensions between English teachers' beliefs and practices in teaching writing. The International HETL Review, 2, 98-114.

Mercer, N. (2009). Developing argumentation: lessons learned in the primary school. In N. Muller Mirza, \& A.-N. Perret-Clermont (Eds.), Argumentation and education (pp. 177-194). New York, NY: Springer. https://doi.org/10.1007/978-0-387-98125-3_7

Neely, M. E. (2014). Epistemonogical and writing beliefs in a first-year college writing course: Exploring shifts across a semester and relationships with argument quality. Journal of Writing Research, 6(2), 141-170. https://doi.org/10.17239/jowr-2014.06.02.3

Peirce, B. N. (1995). Social identity, investment, and language learning. TESOL Quarterly, 29, 9-31. https://doi.org/10.2307/3587803

Pennington, M., \& So, S. (1993). Comparing writing process and product across two languages: A study of 6 Singaporean University student writers. Journal of Second Language Writing, 2, 41-63. https://doi.org/10.1016/1060-3743(93)90005-N

Pessoa, S. (2017). How SFL and explicit language instruction can enhance the teaching of argumentation in the disciplines. Journal of Second Language Writing, 36, 77-78. https://doi.org/10.1016/j.jslw.2017.05.004

Plakans, L., \& Gebril, A. (2017). An assessment perspective on argumentation in writing. Journal of Second Language Writing, 36, 85-86. https://doi.org/10.1016/j.jslw.2017.05.008

Quintana, C., Reiser, B. J., Davis, E. A., Krajcik, J., Fretz, E., Duncan, R. G., et al. (2004). A scaffolding design framework for software to support science inquiry. Journal of the Learning Sciences, 13(3), 337-386. https://doi.org/10.1207/s15327809j1s1303_4

Silva, T. (1990). Second Language Composition Instruction: Developments, Issues, and Directions in ESL. In B. Kroll (Ed.) Second Language Writing (pp.11-23). Cambridge: Cambridge University Press. https://doi.org/10.1017/CBO9781139524551.005 
Starfield, S. (2002). I'm a second-language English speaker: Negotiating writer identity and authority in Sociology One. Journal of Language, Identity and Education, 1(2), 121-140. https://doi.org/10.1207/S15327701JLIE0102_02

Tardy, C. M. (2012). Voice construction, assessment, and extra-textual identity. Research in the Teaching of English, 47, 64-99.

Wan, W. (2014). Constructing and developing ESL students' beliefs about writing through metaphor: An exploratory study. Journal of Second Language Writing, 23, 53-73. https://doi.org/10.1016/j.jslw.2014.01.002

White, M. J., \& Bruning, R. (2005). Implicit writing beliefs and their relation to writing quality. Contemporary Educational Psychology, 30, 166-189. https://doi.org/10.1016/j.cedpsych.2004.07.002

\section{Copyrights}

Copyright for this article is retained by the author(s), with first publication rights granted to the journal.

This is an open-access article distributed under the terms and conditions of the Creative Commons Attribution license (http://creativecommons.org/licenses/by/4.0/). 